\title{
Clinical Events Sequence Number
}

National Cancer Institute

\section{Source}

National Cancer Institute. Clinical Events Sequence Number. NCI Thesaurus. Code C87854.

A number that identifies the ordering relations (in time, space, etc.) in a set of clinical events. 